\title{
A Comparative Study of Vocal Music Art Guidance Courses between China and Russia
}

Jun Su

\author{
College of Music, Chengdu Normal University, Chengdu, Sichuan 610000, China
}

\begin{abstract}
The development of vocal arts instruction courses in China is not too long and the curriculum is still being improved. At the same time, there are many educators and musicians who have misunderstandings about the vocal arts instructional curriculum. Therefore, it is extremely necessary to conduct an in-depth analysis of the vocal art curriculum. This article analyzes the differences between Chinese and Russian vocal arts instruction courses from multiple perspectives and summarizes some experiences. It hopes to provide a reference for the teaching of vocal arts in China.
\end{abstract}

Keywords: Sino-Russian vocal music; art direction; comparative study

\section{Overview of Sino-Russian vocal development}

(1) The development of Russian music

China and Russia are both major educational countries in the world, and Russia has its own characteristics in music teaching. At the earliest times, there was religious music. In the seventeenth century, a special school was established. They were mainly taught religious music, including vocal music and instrumental music. In a sense, the teaching of Russian vocal music begins with the popularization of religious music. In the second half of the 19th century, rapid development began, music classes were set up at all levels and schools and it was a required course. At the same time, a number of professional music schools were also developed. By the beginning of the 20th century, music development in the country was relatively mature. Many outstanding musicians are wellknown all over the world. Although the political situation is turbulent, the inheritance of music has always been very stable, and it has played an important role in the development of music in Russia.

(2) The development of Chinese music

Due to different historical cultures, there is a big difference between Chinese and Russian music. In the period when our country has been in a traditional society for a long period of time and has been developing into a new cultural movement, Western music has been infiltrated. A group of men of insight in China began to learn Western music and believed that China should introduce more advanced concepts before it can enrich music. Initially, China has begun to set up special disciplines to teach music arts from the West and guide people to appreciate Western music, such as operas, arias, etc., to constantly improve the people's musical aesthetic awareness. At the same time, there were also a group of people who loved music, actively studied Western advanced music concepts, improved the method of vocalization, combined the pronunciation method with the actual situation in China, and gave the students the charm of many national music. In the 1930s, musicians began to use ethnic tune as the basis, and combined western voices to create a large number of outstanding works with the background of the times. Therefore, the music of China, Russia and Russia belong to two major factions and each has its own merits. The corresponding comparison between the two will be integrated, which will have a great positive effect on the development of music.

\section{Comparison and Analysis of Vocal Music Art Guidance Courses between China and Russia}

Vocal art guidance is a discipline where practice and theory intersect. Its knowledge and skills cover a wide range, including all aspects of the music field. From piano, vocal music, composition, music, language, and so on, different disciplines will be included in the category of vocal music guidance. This course has its own unique content, rules, logic, and characteristics. It is also an artistic discipline. The vocal art instructor's teaching focuses on teaching students in music processing, style control, and language stage performance. At the same time, it guides students to perceive the sound from the connotation of music.

(1) Comparative Analysis of Curriculum Views of Chinese and Russian Music Art Guidance Courses

The subject of vocal arts instruction is less of a concern. Although it is a common subject for many music schools, it is an unpopular subject and has always been considered as a supporting subject for accompaniment. In 
fact, the real vocal art instruction is very rich in content, not just accompaniment, but also more to understand the background of the song, to correctly grasp the style of learning music, and so on. Only such an interpretation can make music guidance for moving singing. In most of our country, it is thought that artistic instruction is only an instrument accompaniment. This is a misunderstanding. In the vocal arts instruction course, musical instrument accompaniment belongs to the branch of vocal music teaching and helps vocal music teaching. In foreign countries, many vocal art directors are established, such as music schools, opera schools, and so on. The main job is similar to the vocal professional teachers. The teaching focuses more on music style, language, sound, etc., how to control and handle it. The vocalization technique is only one aspect. More layers are based on the charisma of the music itself. Adjusting vocal music learning will allow students to guide how to use sound to express more profoundly and be more explosive.

\section{(2) Comparative Analysis of Curriculum Settings of Chinese and Russian Music Art Guidance Courses}

Specifically, the development of vocal arts instruction in China is not long, just over ten years. Its curriculum is only slightly developed in recent years, so there are still many areas for improvement. Some colleges have set up this major, and they have also divided the two aspects of beauty and nationality. However, more schools are only learning for sophomores and juniors piano students, but they have not become independent professionals. There is no complete system of vocal art instruction in the syllabus and selection of songs for music teaching. The main form of the course is to browse mainly opera fragments, artistic songs, ethnic songs and other forms. And the teaching methods adopted are group lessons, and more are in the development stage of experience teaching. But abroad, such as the St. Petersburg Conservatory of Music, vocal art direction is a specialized course with a professional branch. And it is one of the required courses for piano solo. From the sophomore year you have to learn to graduate, and you have to take the graduate entrance exam. The vocal art instruction at the St. Petersburg Conservatory of Music is an important teaching content for the undergraduate stage. The first year starts with the audition and the requirements for the students are relatively high. The various types of expression terms specified by the composer are expressed in the musical symbols. In the second school year, students were asked to play musical compositions from different periods, and at the same time, they must accurately grasp the musical style. After studying for the third year, students should begin to practice solo and solo exercises. In the fourth year, it began to perform with singers to achieve the effect of stage performances. Therefore, the entire system of vocal music instruction is complete, from theoretical learning to practice, to the final stage of acting, to truly apply knowledge, and must achieve the "performance" effect.

\section{(3) Analysis of the processing of vocal music works in Chinese-Russian music and arts instruction courses}

Chinese arts instruction courses are actually quite limited in the performance of their works. The Belcanus professional is more biased toward Italian and less related to other languages. It focuses on classical works in the selection of tracks, and the selection of tracks is narrow; the technical attention to the works is very limited. More often than not, teachers devote a lot of energy to breakthroughs in student technology. The style characteristics and emotional understanding of the track are not enough. Some Russian foreign teachers are teaching in some music schools in China. They like their own culture very much. In the implementation of the curriculum, the choice of vocal music will favor Russian vocal works, and will also arrange many Russian vocal assignments. For Chinese works they are more concerned with some emotional understanding. For example, some foreign teachers are familiar with the customs and customs of China and like the tone of five tones. When they appreciate the works, they feel that the sound, affection, and character are the most basic requirements for appreciation. This requires that we must pay attention to the mellowness, resonance, and fullness of the tone and the words must be clear. Take "Hometown Love" as an example. When deciphering this song, you should start from the lyrics and meditate on the deep and rich atmosphere of this music. What the concrete lyrics want to express is a village student's thoughts and odes to his hometown. The land he loves is plain and simple, but it is like a sketch of a landscape painting. It is touched without rendering. When playing the piano, the finger range of the finger beating is very wide, this makes this work very inspired. Therefore, when deciphering this song, we must have more levels. We must push the whole song to the climax and sublimate the emotions of the entire song.

\section{(4) Comparative Analysis of Teacher Power in Chinese and Russian Music Art Guiding Courses}

As far as domestic vocal art instruction is concerned, there is a relative shortage of teachers and teaching resources are insufficient. In many colleges and universities, college professional teachers lack art instructors. The number of students is increasing and teachers are not enough. Most of the students do not have professional teacher guidance. They may be guest players of other teachers. This caused the training of the class to have failed to meet the real requirements for the processing of the songs, which greatly influenced the quality of teaching. Moreover, many schools can only have art instructors to cope with the teaching when they are taking the exam or acting. They usually lack communication and vocal instructors do not really enter the classroom. However, in the 
Russian curriculum, vocal instructors are teaching together with the vocal teacher while giving guidance. Vocal music teachers are responsible for skills, and art instructors are responsible for performance and language, and work in cooperation. The classroom efficiency of teachers throughout the classroom will be greatly improved. At the same time, the students' practical ability will be stronger and they will be able to perform better after taking office.

\section{(5) Comparison and Analysis of Teaching Contents of Chinese and Russian Music Art Guidance Courses}

In the vocal arts instructional course, the teaching content is very important. How to choose a suitable singing work plays a key role in the course effect. Through comparative analysis, we can see that the difference between Russia and China is very obvious. In most colleges and universities in China, there is a phenomenon. Teachers like to test students' abilities and define the standard of teaching achievement as "whether or not the performance works are large". "The difficulty of performing works is not high," but students' understanding of the work, expression, and skill handling are ignored. However, in Russia, teachers pay more attention to the performance of music. Singing requires skill, and choosing a work also requires respecting certain laws. Vocal music is actually an abstract subject. It has mastered good methods in the process of practicing sound, but it is not able to effectively perform works. This is because vocal music works are actually made up of many elements. In addition to good sound conditions, they must also have others, such as melody, rhythm, strength and weakness, language, culture, emotion, deduction methods, and performance of sound. Dimensions are effectively played to truly show the charm of a musical work. In contrast, Chinese teaching has also been influenced by a large number of examoriented education, and there is still a relatively lack of guidance on the values of emotional attitudes.

\section{(6) Comparative Analysis of the Teaching Forms of Chinese and Russian Music Art Guidance Courses}

The form of teaching is a method of expression of a course, and so is vocal music teaching. Through the comparative analysis of the teaching curriculum setting, we can find that the Sino-Russian vocal arts instruction courses are based on one-on-one teaching, supplemented by big classes. However, Russia's one-on-one will always go through and pay more attention to the teaching mode of the same department. However, in China's universities, one-on-one teaching is relatively low. Moreover, different colleges and universities have taken different courses. One-on-one, group lessons, and large-scale classes were in parallel. Group lessons have sometimes replaced one-on-one, while major classes have become the main theme. The vocal music subject is very special. The one-on-one model can correct mistakes better. This is a practical, imitative, and emotional crossover subject. Students have different voice conditions and can show different musical works.

\section{Experience summary}

Through comparative analysis, we have found that there are many teaching methods worth learning from in Russia. Here are some points.

(1) Increase the impact of multimedia on the classroom

With the rapid development of information technology, people's lifestyles have undergone tremendous changes, which have also provided greater support for education. In vocal music teaching, multimedia technology can make teaching more diversified and enriched. Various resources are coordinated and integrated by teachers and schools and can be fully utilized in vocal music teaching. Let more excellent resources infiltrate the classroom and break through the limitations of time, place and space. Let students feel more advanced and good music, experience the local customs and music styles of different local music, and be immersed in the environment to strengthen the perception of music. At the same time, it is also possible to popularize the content of foreign arts instruction courses and improve the effectiveness of vocal music instruction courses.

\section{(2) Strengthen music practice activities}

Through the comparison of the content of the Sino-Russian curriculum, it is found that among the pedagogic goals, foreign music focuses more on the performance of acting on stage, and in this respect China's education must also be strengthened. In colleges and universities, we must prepare more stage performances to provide students with enough performance opportunities to improve the overall performance of the music vocal level. At the same time, we must effectively use resources, broaden our thinking, create more opportunities for practice, and allow students to participate in more music performance works. 
(3) Strengthening the scientific teaching of music

Vocal music teaching is also a subject, its teaching must be increasingly scientific, and the national symbols are infiltrated into music education. From the point of view of vocal music development, vocal music teaching continues to introspect and enhance self-knowledge. This is a self-conscious effect. Through the integration with other disciplines, we can deepen our understanding of vocal lessons. Correctly understand the charm of Chinese music. And science is also closely related to the quality of talent. Therefore, the development of scientific teaching content is the trend of future vocal music teaching. Only by continuously improving the scientific nature of vocal music teaching can we cultivate a scientific education concept and cultivate vocal music students with scientific culture and culture, so as to shape the future of Chinese music.

\section{Conclusion}

The stone of other hills can be used to study jade. The contrast is to study. Through the comparative analysis of the vocal music teaching guidance between China and Russia, the ultimate goal is to learn advanced teaching concepts and combine it with the actual national conditions of China to make up for vocal music teaching. Insufficient, continuous improvement, and explore a more suitable method of sound education in China. With the rapid progress of society, music teaching concepts and concepts are also changing. Many music schools have begun to explore new ways, not only to learn from Russian ideas, but also to learn from the teaching concepts of more countries. Conduct a variety of foreign exchange activities, interactive activities, learn from each other and continue to explore. It is believed that under the efforts of these outstanding music educators, Chinese vocal music teaching will make greater progress. Art curriculum guidance can also play a greater role in teaching and promote the development of mus

\section{Acknowledgements}

[1] Southwest China Music Research Center, Sichuan Provincial Social Science Key Research Project General Project “Comparative Study on the Development of Sino-Russian Vocal Art Guiding Teaching” (xnyy2016020), Principal Investigator, Under Research (2016.07-2018.07).

[2] Sichuan Province Philosophy and Social Research Key Research Base Sichuan Province Primary and Secondary School Teacher Professional Development Research Center General Project "Study on the Selfembelling and Self-Singing Cultivation Mechanism of Chinese and Russian Music Teachers" (PDTR2017-25), Principal Investigator, Under Research (2017.06-2018.06).

[3] General Project of Sichuan Provincial Department of Education "Comparative Study on Self-emudo and Selfsinging Course System of Chinese and Russian Musical Education”, 2018 SB0085, Principal Investigator, Under Research (2017.11-2018.12).

[4] Key Project of the Basu Music Institute of Chengdu Normal University "Comparative Study between the Chinese and Russian Modern Educations in Vocal Art Guiding”, Principal Investigator, Under Research (2018.052019.07).

\section{References}

[1] Chen Mingkong. Viewing Music Education in China from the Achievement of Russian Music Education [J]. Hainan University Newspaper, 2006 (3).

[2] Yu Hong. Awareness and Reflection on Russian Music Education [J]. Art Education, 2006(6).

[3] Zhu Xi. A comparative study of Sino-Russian vocal music teaching _ Interviews with the Belarusian State Conservatory of Music [D]. Chongqing: Master thesis of Southwest University, 2007. 